\title{
Regulation of TIMP-1 in Human Placenta and Fetal Membranes by lipopolysaccharide and demethylating agent 5-aza-2'-deoxycytidine
}

\author{
Zoë L. Vincent ${ }^{1,2}$, Murray D. Mitchell ${ }^{1,3}$ and Anna P. Ponnampalam ${ }^{1,2,4^{*}}$
}

\begin{abstract}
Background: An appropriate transcriptional profile in the placenta and fetal membranes is required for successful pregnancy; any variations may lead to inappropriate timing of birth. Epigenetic regulation through reversible modification of chromatin has emerged as a fundamental mechanism for the control of gene expression in a range of biological systems and can be modified by pharmacological intervention, thus providing novel therapeutic avenues. TIMP-1 is an endogenous inhibitor of MMPs, and hence is intimately involved in maintaining the integrity of the fetal membranes until labor.
\end{abstract}

Objective and Methods: To determine if TIMP-1 is regulated by DNA methylation in gestational tissues we employed an in vitro model in which gestational tissue explants were treated with demethylating agent 5-aza-2'deoxycytidine (AZA) and lipopolysaccharide (LPS).

Results: Quantitative Real-Time PCR (qRT-PCR) revealed that TIMP-1 transcription was significantly increased by combined treatment of AZA and LPS, but not LPS alone, in villous, amnion and choriodecidua explants after 24 and 48 hrs, whilst western blotting showed protein production was stimulated after 24 hrs only. Upon interrogation of the TIMP-1 promoter using Sequenom EpiTyper MassARRAY, we discovered sex-specific differential methylation, in part explained by $x$-linked methylation in females. Increased TIMP-1 in the presence of LPS was potentiated by AZA treatment, signifying that a change in chromatin structure, but not in DNA methylation at the promoter region, is required for transcriptional activators to access the promoter region of TIMP-1.

Conclusions: Collectively, these observations support a potential role for pharmacological agents that modify chromatin structure to be utilized in the therapeutic targeting of TIMP-1 to prevent premature rupture of the fetal membranes in an infectious setting.

Keywords: TIMP1, Placenta, Labour, Epigenetics, Infection

\section{Background}

The end of human gestation is signified by the physiological hallmarks of uterine contractions and rupture of the fetal membranes (amnion and chorion) [1]. These two processes are essential for the advancement of labor, and inappropriate timing of these processes may lead to

\footnotetext{
* Correspondence: a.ponnampalam@auckland.ac.nz

'Liggins Institute, University of Auckland, Private Bag 92019, Auckland 1142, New Zealand

${ }^{2}$ Gravida: National Centre for Growth and Development, Palmerston North, New Zealand

Full list of author information is available at the end of the article
}

premature or post-term birth, both of which have adverse consequences for the neonate $[1,2]$.

Matrix metalloproteinase (MMP) mediated extracellular matrix (ECM) degradation plays a key role in normal growth and remodelling of fetal membranes throughout gestation and at term, and are critically involved in the weakening and subsequent rupture of the fetal membranes at the time of labor [3]. Locally produced tissue inhibitors of metalloproteinases (TIMPs) function as critical modulators of both normal and pathological tissue remodelling. As TIMPs bind MMPs in a 1:1 stoichiometric 
fashion, thus an imbalanced MMP:TIMP ratio can result in tissue degradation.

TIMP-1 levels decrease in the amniotic fluid with advancing gestation, concomitant with a marked increase in MMP-9 prior to the onset of labor [4-8]. Increased MMPs, particularly MMP-9, in fetal membrane rupture at both preterm and term labor is well documented [6, 7, 9-13] and the MMP-9:TIMP-1 ratio in fetal membranes at term gestation correlates with their tensile strength [14]. Furthermore, this altered MMP-9:TIMP-1 ratio is exacerbated in the presence of infection [7, 15-19].

Preterm rupture of the fetal membranes (PROM) occurs in as many as $15 \%$ of all pregnancies and is associated with $25-50 \%$ of preterm births $[20,21]$. The etiology of preterm labor is complex and multifactorial, however intrauterine infection caused by bacteria is the leading identifiable cause [1, 22]. Lipopolysaccharide (LPS), an endotoxin on the outer surface of gram negative bacteria, has been implicated in the mechanism responsible for PROM and preterm delivery [23, 24].

Epigenetic regulation through the reversible modification of chromatin has emerged as a fundamental mechanism for the control of gene expression in a range of biological systems. DNA methylation is the covalent modification of post-replicative DNA by the addition of a methyl group to the cytosine ring to form methyl cytosine, usually in the context of CPG dinucleotides. Discrete $\mathrm{CpG}$ rich regions, approximately $1 \mathrm{~kb}$ in size, are known as CpG islands (CGIs) and occur in more than half of the genes in the vertebrate genome [25]. CGIs are usually unmethylated, and the extent of methylation in promoter regions is generally inversely correlated with gene activity [26, 27]. Epigenetic modifications are subject to both developmental and environmental regulation, are reversible and can potentially be modified, thereby making them an attractive target for therapeutic interventions.

DNA methylation is essential for normal development of extra-embryonic tissues, particularly the invasive behavior of trophoblast cells [28]. The placenta is unique in that it is hypomethylated compared to somatic tissues $[29,30]$, and DNA methylation is positively correlated with gestational age $[31,32]$. This suggests that there are consistent and large scale changes to DNA methylation in the placenta throughout pregnancy, contributing to differential global gene expression across gestation [33] and at term prior to, and following, spontaneous labor and delivery [34, 35].

Silencing of TIMP- 1 by promoter methylation is a feature of cancer cells, and treatment with demethylating agent AZA results in the induction of TIMP-1 in a number of cancer cell lines [36-40] as well as endometrial stromal cells [38].
Given that aberrant placental methylation has been associated with adverse pregnancy outcomes [39-41], and TIMP-1 is regulated by DNA methylation in other tissues; we hypothesize that TIMP-1 is regulated by DNA methylation in the placenta and fetal membranes, and that this regulation is altered in the presence of infection.

\section{Methods}

\section{Tissue Collection and explant system}

Gestational tissues (villous placenta and fetal membranes) were collected from women at term with uncomplicated, singleton pregnancies (38-40 weeks gestation) following elective caesarean section (pre-labor, CS) and after vaginal delivery from women with spontaneous onset of labor (post-labor and delivery, SVD). Indications for cesarean section were breech presentation or previous cesarean section delivery. Women were excluded from the study if they had a twin pregnancy, became pregnant using in vitro fertilization, suffered any pregnancy complications including preeclampsia or gestational diabetes, were a current smoker, or smoked up until, or during any part of their pregnancy. Ethical approval for the study was obtained from NorthernX Regional Ethics Committee (NTX/10/ 07/062/AM03) and tissues were collected following written informed consent. All the participants have given consent to publish the data. The fetal membranes were separated into amnion and chorion (with the immediately adjacent decidua attached, herein referred to as choriodecidua), and all tissues were rinsed in PBS to remove maternal blood. Tissues from both CS and SVD deliveries were snap frozen and stored at $-80 \mathrm{C}$ until further analysis. Tissues from CS deliveries were cultured using a previously published in vitro tissue explant system [42-44] with modifications as follows.

Samples of villous tissue were taken randomly across the placenta from mid-sections of cotyledons (halfway between the maternal and fetal sides). Large vessels were removed using blunt dissection leaving only villous tissue, which was further dissected into $20 \mathrm{mg}$ pieces. Fetal membranes were separated into amnion and choriodecidua and $6 \mathrm{~mm}$ tissue discs were excised using a sterile cork borer. Villous, amnion and choriodecidua explants were plated separately (six pieces per well) and equilibrated in DMEM/F12 containing L-Glutamate (Life Technologies, Carlsbad, CA, USA) with 10 \% FBS (Life Technologies) and $1 \%$ Penstrep solution (final concentrations $100 \mathrm{U} / \mathrm{ml}$ Penicillin and $100 \mu \mathrm{g}$ streptomysin; Life Technologies) in a humidified atmosphere of $5 \% \mathrm{CO}_{2}$ and $8 \% \mathrm{O}_{2}$ for $24 \mathrm{hrs}$.

After equilibration, tissues were washed and media were replaced with DMEM/F12 supplemented with $0.1 \%$ bovine gamma globulin (Sigma-Aldrich, St. Louis, MO, USA) containing $5 \mu \mathrm{M}$ AZA (Sigma-Aldrich) or DMSO 
as the control (Sigma-Aldrich). Media for all treatments contained $0.05 \%$ DMSO. The dose and length of AZA treatment was based on previous publications [45]. Following 48 hrs culture, tissues were extensively washed in sterile PBS and tissues were further incubated in the presence or absence of $5 \mu \mathrm{g} / \mathrm{ml}$ LPS (E.coli, Sigma-Aldrich). Tissues were cultured with LPS to determine if an inflammatory response induced changes in TIMP-1 expression and/or DNA methylation. Control tissues were cultured in DMSO only for the duration of the culture period, with exception of the initial 24 hrs equilibration period. Culture was terminated at $24 \mathrm{hrs}$ and $48 \mathrm{hrs}$ post LPS treatment, tissues were snap frozen and conditioned media reserved. Tissues and media samples were stored at $-80 \mathrm{C}$ and $-20 \mathrm{C}$ respectively.

\section{Glucose uptake by tissue explants}

Tissue viability was assessed by glucose uptake in conditioned media from explant experiments (Reti, Lappas, Huppertz, et al., 2007). Glucose uptake was measured by enzymatic colourimetric assay (Roche, Mannheim, Germany) on a Hitachi 902 autoanalyser (Hitachi High Technologies Corporation, Tokyo, Japan). Data were normalised to wet tissue weight and minutes (Table 1).

\section{RNA Extraction and Real time PCR}

Total RNA was isolated from tissues using Trizol $^{\circ}$ (Life Technologies) according to manufacturer's instructions. RNA concentrations were quantified using a NanoDrop ND-1000 spectrophotometer (NanoDrop, Thermo Scientific, USA). Reverse transcription and cDNA synthesis was performed using Transcriptor First Strand cDNA Synthesis Kit (Roche Applied Sciences, Penzberg, Germany) according to manufacturer's instructions using $1 \mu \mathrm{g}$ of total RNA for each preparation. The resulting cDNA was stored at $-20 \mathrm{C}$ until required.

TIMP-1 expression was analysed by Quantitative RealTime PCR (qRT-PCR) using the LightCycler 480, LightCycler 480 SYBR Green Master Mix (Roche Applied Sciences). Gene specific primers used for qRT-PCR are as follows. TIMP-1: sense 5'-TCTGGCATCCTGTTG TTGCT-3'; antisense 5'-CGCTGGTATAAGGTGGTC TGG-3'. RPLPO: sense 5'AGAAACTGCTGCCTCAT ATCCG-3'; antisense 5'-CCCCTGGAGATTTTAGTGG TGA-3'. RPL13a: sense 5'-GCCCTACGACAAGAAAA
AGCG-3'; antisense 5'-TACTTCCAGCCAACCTCGTGA3' (Integrated DNA Technologies, Custom Science, Auckland, New Zealand). Primer specificity was confirmed by the Massey Genome Service at Massey University, Palmerston North, New Zealand. RPLPO and RPL13a were used as endogenous controls to normalise gene expression. The average transcript quantity in tissues collected from CS and SVD deliveries and in treated tissue explants was calculated using the relative standard curve method and Delta-delta CT method respectively, normalised to the geometric mean of the endogenous controls.

\section{Western blotting}

Western blotting was performed on whole cell lysates using rabbit monoclonal anti-TIMP-1 antibody (ab109125, Abcam, Cambridge, UK). Samples were separated by weight by SDS-PAGE using 4-12\% Bis-Tris gels (Life Technologies), and transferred onto PVDF membrane. Following pre-incubation with a blocking solution, membranes were incubated in primary antibody overnight. The membranes were then extensively washed, incubated in HRP-conjugated secondary antibody (A5045, Sigma Aldrich) and were visualized using Pierce SuperSignal West Dura Extended Duration Substrate (Thermo Scientific, Illinois, USA). Relative protein levels were obtained using densitometric quantification (Quantity One software; Bio-Rad Laboratories, Hercules, California, USA) and were normalized to beta actin.

\section{DNA Extraction and Methylation Analysis}

Genomic DNA was extracted from tissues using Qiagen QiaAMP DNA extraction kit (QIAGEN, Hilden, Germany) as per manufacturers' instructions. DNA concentrations were quantified using a NanoDrop ND-1000 spectrophotometer.

Methylation analysis using the Sequenom ${ }^{\text {tu }}$ EpiTyper $^{\circ}$ MassARRAY platform was undertaken by the Australian Genome Research Facility (AGRF; www.agrf.org.au). Sequenom primers specific to two regions of the TIMP1 gene were designed in-house by AGRF. Region A is upstream from the transcription start site $(-275 /-1)$ covering $11 \mathrm{CpGs}$ and Region B includes the TIMP-1 promoter and first exon, covering 14 CpGs (Fig. 1). Methylation analysis was carried out on bisulphite converted DNA, using $200 \mathrm{ng}$ for each preparation.

Table 1 Glucose uptake by gestational tissue explants

\begin{tabular}{|c|c|c|c|c|c|c|c|c|}
\hline & \multicolumn{4}{|l|}{$24 \mathrm{hrs}$} & \multicolumn{4}{|l|}{$48 \mathrm{hrs}$} \\
\hline & Control & AZA & LPS & $A Z A+L P S$ & Control & AZA & LPS & $A Z A+L P S$ \\
\hline Placenta & $0.80 \pm 0.13$ & $0.92 \pm 0.09$ & $0.79 \pm 0.08$ & $0.86 \pm 0.06$ & $0.43 \pm 0.04$ & $0.63 \pm 0.02$ & $0.49 \pm 0.05$ & $0.48 \pm 0.06$ \\
\hline Amnion & $0.98 \pm 0.02$ & $0.92 \pm 0.02$ & $0.86 \pm 0.03$ & $0.91 \pm 0.02$ & $0.84 \pm 0.02$ & $0.85 \pm 0.01$ & $0.76 \pm 0.02$ & $0.73 \pm 0.01$ \\
\hline Choriodecidua & $0.43 \pm 0.03$ & $0.47 \pm 0.07$ & $0.41 \pm 0.06$ & $0.40 \pm 0.06$ & $0.38 \pm 0.05$ & $0.41 \pm 0.04$ & $0.39 \pm 0.03$ & $0.45 \pm 0.04$ \\
\hline
\end{tabular}

Glucose uptake by placenta, amnion and choriodecidua explants was measured in conditioned culture media by enzymatic colourimetric assay.

Data are presented as glucose uptake $\mu \mathrm{mol} / \mathrm{mg} / \mathrm{min}(\operatorname{mean} \pm \mathrm{SEM} ; \mathrm{n}=8$ ) 


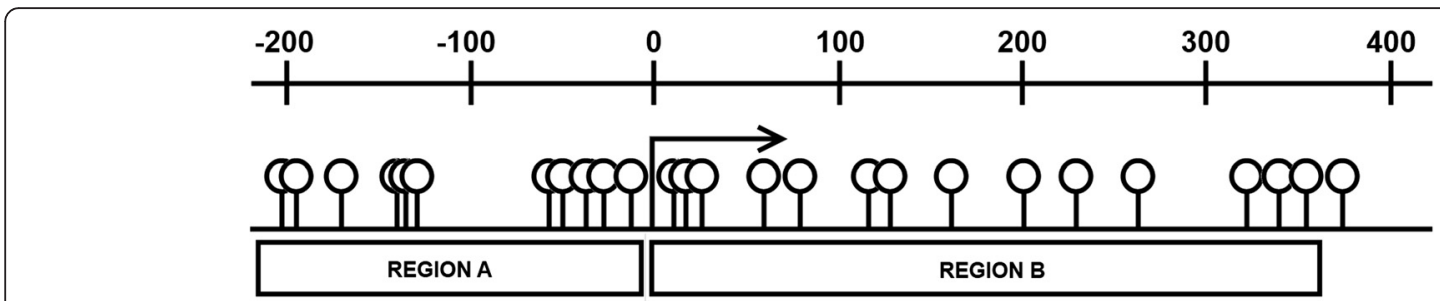

Fig. 1 Schematic of the TIMP-1 gene promoter and locations of primers used for methylation analysis. Region A is upstream of the transcription start site $(-275 /-1)$ and covers 11 CpGs, Region B (+1/+279) covers the TIMP-1 promoter and first exon and contains 14 CpGs. The numbered line represents the distance in base pairs from the transcription start site, shown by the number 0 . CpGs are represented by open circles

Methylation levels for each CpG unit are expressed as a percentage which is calculated from the ratio mass signals between methylated and non-methylated DNA in each sample.

\section{Statistical Analysis}

Data are presented as means \pm SEM and statistical comparisons between groups were performed using nonparametric Kruskal Wallis ANOVA (1-way analysis of variance) with Dunn's post-hoc test using GraphPad Prism (GraphPad Software, La Jolla California USA, www.graphpad.com). An alpha value of less than 0.05 was considered significant.

\section{Results}

\section{Expression of TIMP-1 in Gestational Tissues in relation to labor}

TIMP-1 mRNA levels were significantly higher in villous tissues collected from elective caesarean section deliveries, prior to the onset of labor (CS) compared to tissues collected following spontaneous vaginal delivery (SVD). This trend was observed also in choriodecidua, but not in amnion tissues (Fig. 2a). Tissues from both CS and
SVD had significantly higher TIMP-1 mRNA in female amnion compared to male amnion (Fig. $2 \mathrm{~b}$ and c).

\section{Effect of AZA and LPS treatments on TIMP-1 transcription and protein production}

Placenta, amnion and choriodecidua tissues pre-treated with AZA and subsequently treated with LPS for both $24 \mathrm{hrs}$ and $48 \mathrm{hrs}$ significantly increased TIMP-1 mRNA expression compared to controls (Fig. 3). LPS treatment alone, without pre-treatment of AZA, had no effect on TIMP-1 transcription. Further scrutiny of the data revealed a greater stimulation of TIMP-1 transcription in male villous and amnion that were pre-treated with AZA compared to female tissues in 48 hour treated tissues (Fig. 3d and e).

Villous and amnion explants pre-treated with AZA and subsequently incubated in the presence of LPS for $24 \mathrm{hrs}$ had significantly higher TIMP-1 protein production compared to controls (Fig. 4a and b). As with the mRNA, LPS treatment alone had little effect on TIMP-1 protein production in villous (Fig. 4a) or amnion explants (Fig. 4b) however did significantly increase TIMP-1 protein in choriodecidual explants following 24 hrs incubation (Fig. 4c). No changes in TIMP-1 protein production were observed in tissues cultured with LPS for 48 hrs (Fig. 4).
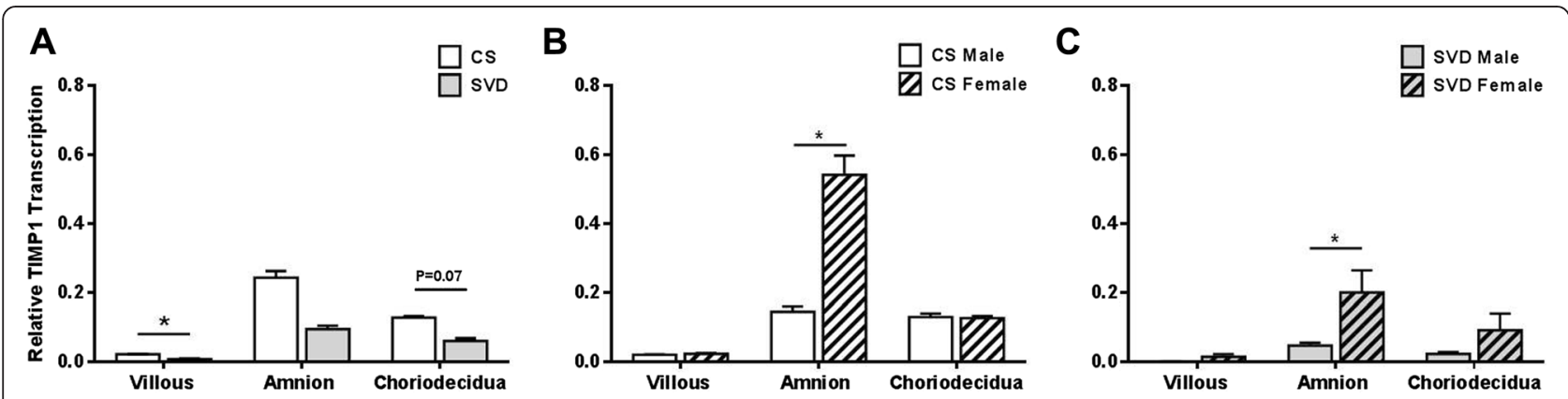

Fig. 2 TIMP-1 mRNA Expression in Term Villous Placenta, Amnion and Choriodecidua measured by qRT-PCR. a Tissues collected prior to the onset of labor from elective Caesarean sections deliveries $(C S, n=14)$ are shown by the white bars. Tissues collected following the spontaneous onset of labor from vaginal deliveries (SVD, $n=10$ ) are shown by grey bars. TIMP-1 transcription was further analysed by sex of the fetus in $\mathbf{b} C S$ deliveries (Male $n=8$, Female $n=6$ ) and $\mathbf{c}$ SVD (Male $n=5$ and Female $n=5$ ). Data are presented as mean \pm SEM $* P \leq 0.05$. All results were normalised to the expression of endogenous controls (RPLPO and RPL13a) 


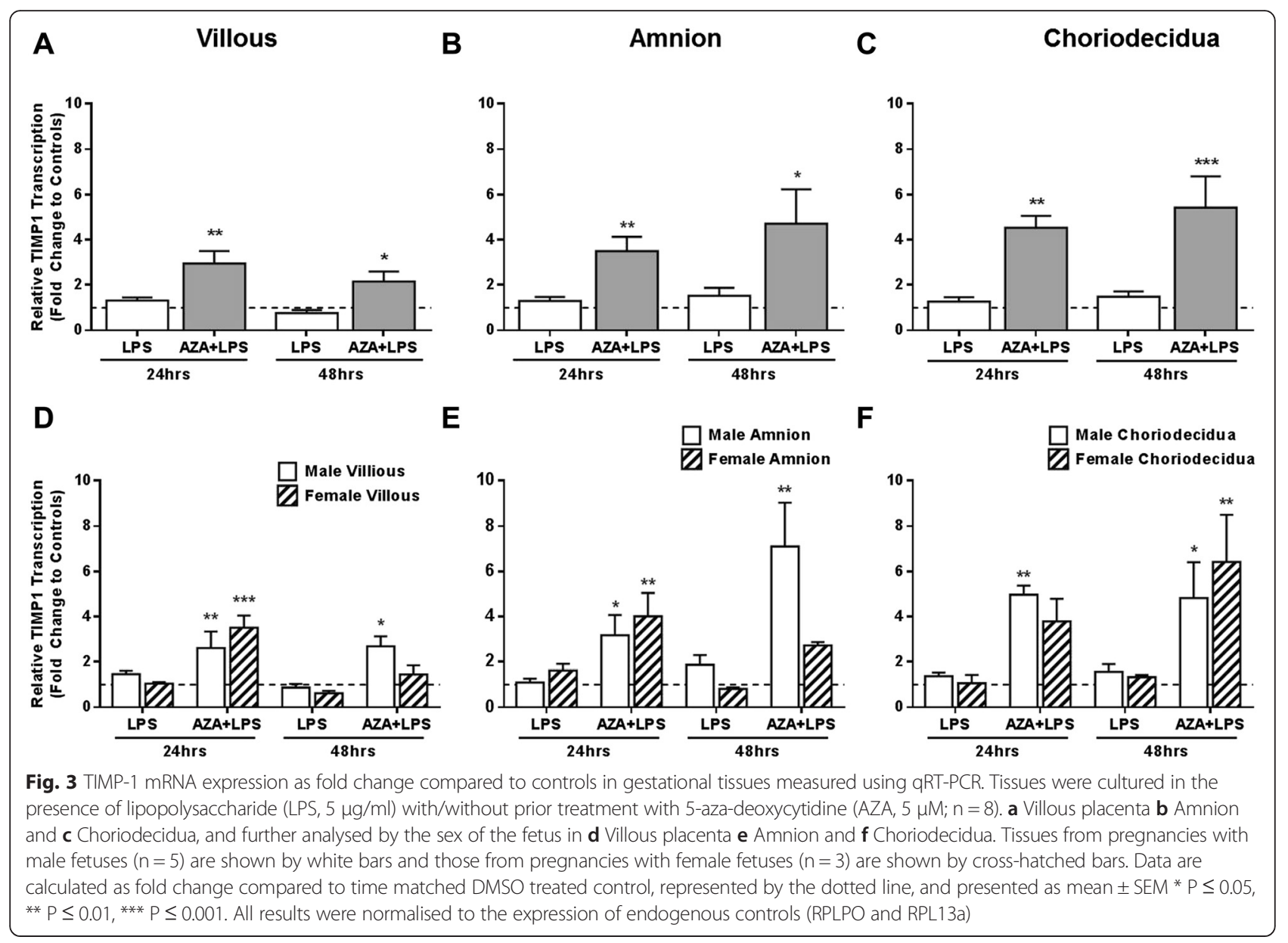

Similar to the mRNA data, there appears to be a sexspecific response of TIMP-1 protein production to the treatments, particularly in male choriodecidua treated for 48 hrs (Fig. 4f). Although notable, high variations among sample groups prevent statistical significance.

\section{Methylation analysis of TIMP-1}

Methylation within the TIMP-1 promoter was significantly higher in amnion from CS deliveries compared to SVD (17 \% and $8 \%$ respectively) (Fig. 5a). Villous and placenta from pregnancies with a male fetus were hypomethylated compared to tissues from pregnancies with female fetuses in both CS and SVD samples (CS villous male $3.5 \%$, female $7.8 \%$; CS amnion male $3.9 \%$, female 25.9 \%; SVD villous male $3.7 \%$, female $8.9 \%$; SVD amnion male $3.2 \%$, female $24 \%$ ). Choriodecidua from pregnancies with male fetuses were hypomethylated compared to choriodecidua from pregnancies with female fetuses in SVD alone (16\% and $22 \%$, respectively) (Fig. $5 \mathrm{~b}$ and c). This was evident in both regions of the TIMP-1 promoter analysed (only data from region $B$ is shown). The percentage methylation of each $\mathrm{CpG}$ is shown in the representative epigram for each tissue (Fig. 5d).

Cultured villous placenta and amnion from pregnancies with male fetuses were hypomethylated compared to tissues from female pregnancies (on average: villous male $4.7 \%$, female $9.6 \%$; amnion male $5.35 \%$, female $29.5 \%$; Fig. 6a and b). Amnion from pregnancies with female fetuses cultured in the presence of LPS had significantly higher methylation compared to controls (34.6\% and $20.6 \%$, respectively; Fig. 6b). Methylation of choriodecidua from pregnancies with female fetuses was significantly higher following treatment with AZA and LPS compared to choriodecidua from pregnancies with male fetuses (26.8 \% and $19.2 \%$, respectively; Fig. 6c).

\section{Discussion}

The present study investigated the regulation of TIMP-1 by DNA methylation with or without infection in the human placenta and fetal membranes. We observed a labor effect on TIMP-1 transcription in villous placenta, and discovered sex-specific differential expression in amnion collected both prior to and post labor and delivery. 


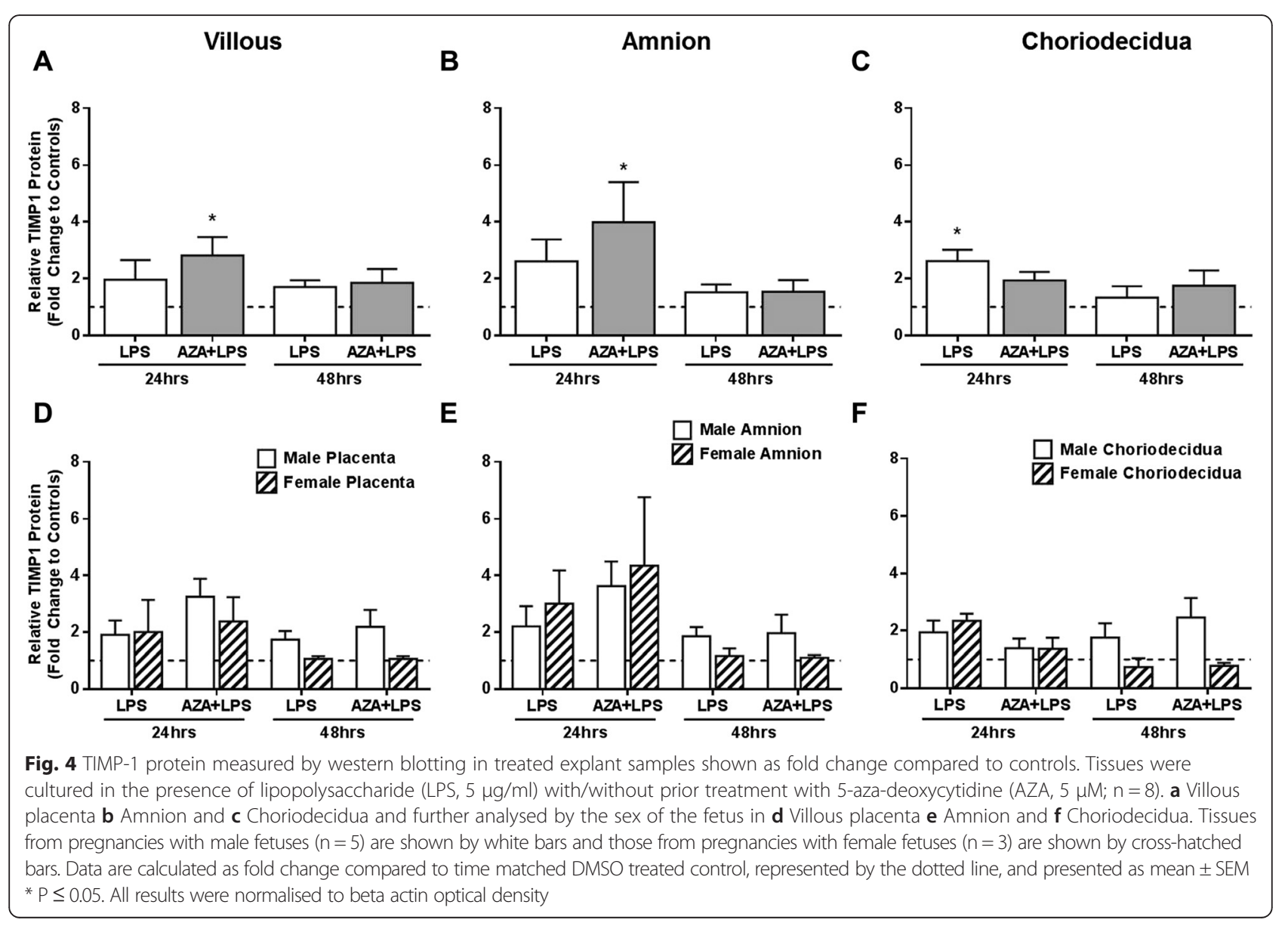

There were subtle differences in methylation in all tissues in relation to labor status, which was discordant with the gene expression observed. The TIMP-1 promoter was generally hypomethylated, particularly in villous placenta, however sex specific methylation patterns were observed. Methylation in villous placenta and amnion from pregnancies with female fetuses was markedly higher than tissues from pregnancies with male fetuses, whereas the levels in choriodecidua were comparable. Treatment with demethylating agent AZA followed by incubation with LPS significantly increased TIMP-1 mRNA, and to a lesser extent protein, in cultured tissue explants. Villous placenta and amnion from pregnancies with male fetuses showed greater stimulation of TIMP-1 transcription following $48 \mathrm{hrs}$ of treatment. This is the first study to show sex-specific expression patterns of TIMP-1 in term gestational tissues.

TIMP-1 is on the X chromosome and is consequently subject to $\mathrm{X}$ chromosome inactivation in females. The fact that higher methylation levels were observed in female tissues in this study was not surprising, as methylation of X-linked genes is enriched on the inactivated $\mathrm{X}$ chromosome [46, 47]. However, not all X-linked genes are completely silenced, and TIMP-1 is reported to display variable inactivation due to both changes in methylation and chromatin structure [48, 49]. With the exception of genes which do escape $\mathrm{X}$ inactivation, $\mathrm{X}$ linked promoters should show limited methylation in males and partial methylation in females [50]. X-linked methylation explains the differences in methylation observed in tissues from pregnancies with male or female tissues collected prior to, and post labor and delivery, and the associated discordant gene expression seen in amnion samples. However, complete inactivation of one $\mathrm{X}$-chromosome should result in a gene showing at least $50 \%$ methylation, which was not the case in all tissues from pregnancies with female fetuses tested, thus suggesting variable inactivation.

A comparison of autosomal and X-lined genes showed that methylation of placental promoters is reduced only on the X chromosome, and is particularly evident in females resulting from an $\mathrm{X}$ - specific methylation decrease [51]. Due to the fact that X-linked placental genes are not usually over expressed, other epigenetic marks, such as chromatin modifications and non-coding RNA, are likely involved in the silencing of $\mathrm{X}$-linked genes, 


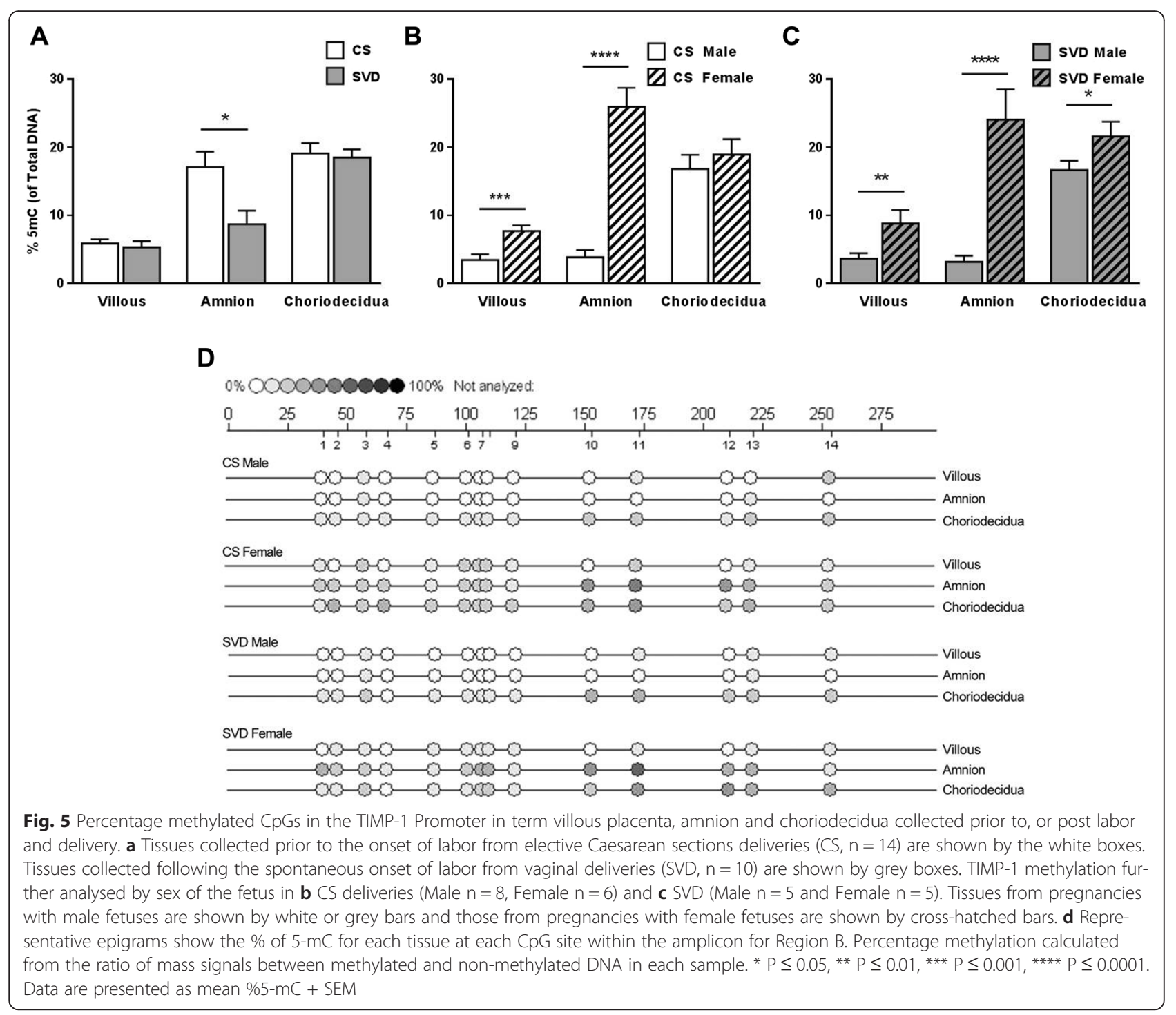

including chromatin changes and non-coding RNA [52]. It is possible that other epigenetic marks are regulating TIMP-1 in the placenta.

The levels of methylation we observed in choriodecidua samples did not differ between tissues from pregnancies with male or female pregnancies. This could be explained in part by the contamination of adjacent maternal cells in the tissue sample. The chorion is closely associated to maternal decidua cells, which are firmly adhered to the chorion membrane. Due to tissue explant system used, it was not possible to separate the fetal cells from the maternal cells, thus no analysis could be carried out on the contribution of either cell's contribution to the gene expression observed. It would therefore be an interesting avenue for future studies to investigate. Despite the presence of maternal cells in male tissue samples, as there is still one active allele in maternal tissues the X-linked methylation cannot alone account for the lessened response of TIMP-1 transcription and protein to treatments seen in cultured tissue explants from pregnancies with female fetuses when compared to tissues from pregnancies with male fetuses. However, the greater response observed in tissues from pregnancies with male fetuses could simply be due to them being more susceptible to the LPS treatment [53].

Tissue and sex-specific differential methylation was observed in both tissues collected at term prior to, and post labor and delivery, and in treated explants. Increased gene expression in the presence of greater methylation could be due to the mixture of silent methylated cells and expressing unmethylated cells in the tissues [54]. It is becoming increasing apparent that DNA methylation may not just function in gene silencing, increased methylation has been associated with enhanced gene expression for several genes including IL8, EGRF-2, HLA-DRA and GPH- $\alpha$ [55-59]. 


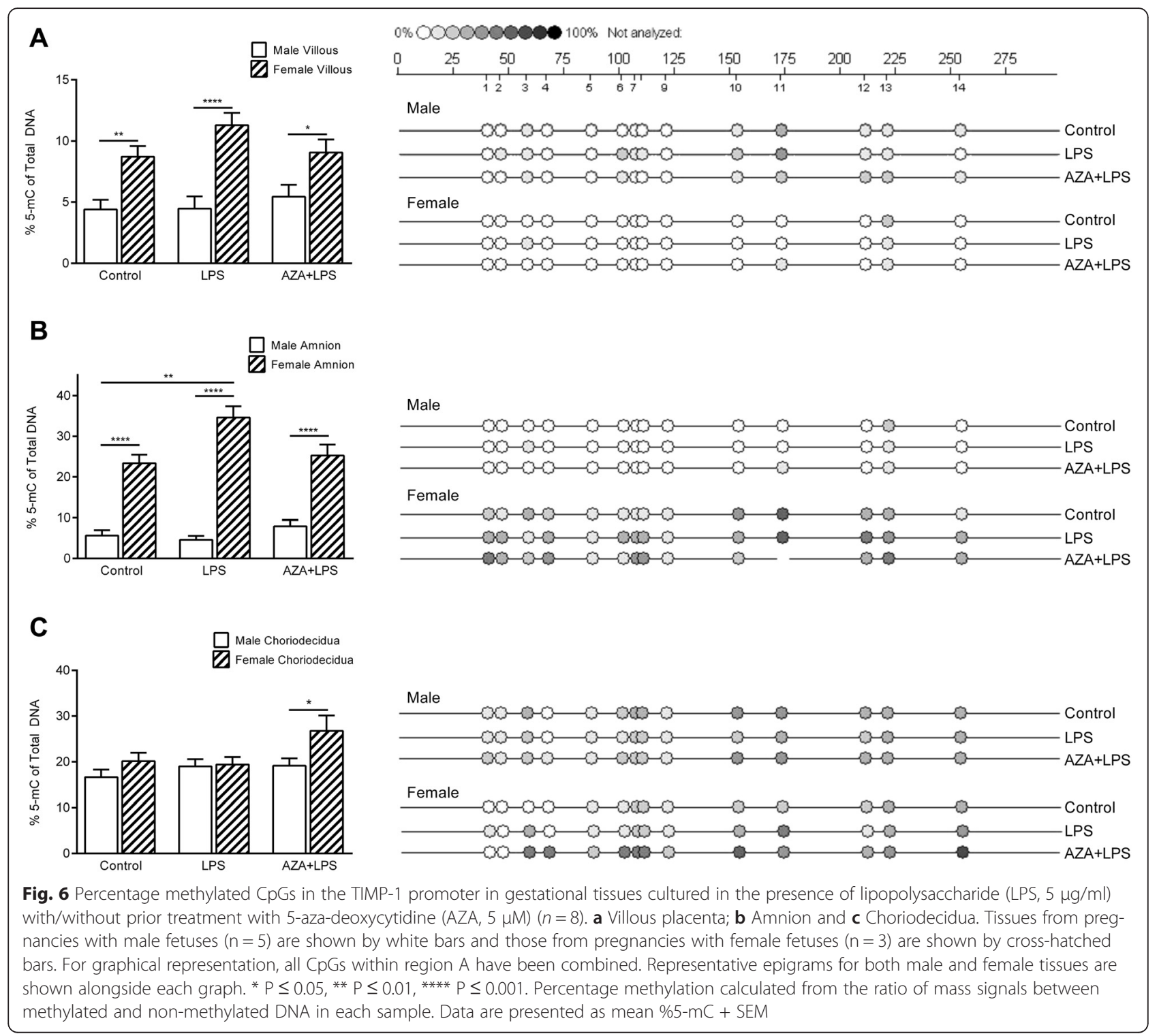

Aside from one time-point in choriodecidua explants, TIMP-1 transcription or protein was not changed with LPS treatment alone. This is in agreement with other studies which have also reported no change in TIMP-1 levels in the placenta and/or fetal membranes following LPS stimulation $[17,19,60]$. These studies did however report an associated increase in MMP-9, thereby altering the MMP:TIMP ratio and favouring a gelatonlytic state. Evidence of LPS associated stimulation of MMP-9 is conflicting; there are a number of reports of increased MMP-9 mRNA and activity in response to LPS stimulation, $[5,59,6$

1] whilst others report that fetal membranes are unresponsive to LPS, suggesting upstream mediators of MMPs such as prostaglandins and/or pro-inflammatory cytokines are required [61, 62].

AZA is a demethylating agent that is incorporated into the DNA as a cytidine analogue, preventing methylation by irreversibly binding DNMT1 [63]. The resulting loss of DNMT1 leads to passive hypomethylation of the genome over successive rounds of cell division, which may have effects on upstream regulators of TIMP-1. Treatment with AZA has previously been shown to induce TIMP-1 expression and protein production in cell culture models [39-43]. Treatment of tissue explants with AZA alone did not alter TIMP-1 expression or protein (data not shown). Our tissue culture model utilized tissue explants rather than cell lines, and in light of this, AZA may not have fully incorporated into the DNA, 
resulting in reduced action and less pronounced hypomethylation [64]. Although we did not measure proliferation in the tissue explants, glucose uptake by the tissue explants was measured in culture media and confirmed that tissues remained viable throughout the culture period (Table 1). AZA could be directly interacting with transcription factors [65] or re-organizing chromatin in such a way that regulatory regions within the promoter are exposed [66-68], thus facilitating binding of transcription factors which are increased in the presence of infection. We saw little variation in both TIMP-1 promoter-specific and global methylation (data not shown) in response to the explant treatments; therefore the increased TIMP-1 transcription observed in tissues pre-treated with AZA and subsequently cultured with LPS indicates that TIMP-1 activation appears to require an AZA-induced change in chromatin structure, such that DNA binding sites in the promoter region become accessible to transcriptional activators. The TIMP-1 promoter contains both ETS and AP-1 binding sites, which, once bound by effector proteins could potentiate enhanced TIMP-1 transcription [51]. Work on human hypoxanthine phosphoribosyltransferase (HPRT) and human-mouse phosphoglycerate kinase-1 (PK-1) genes suggest that $\mathrm{X}$-linked genes are unlikely to be primarily silenced by DNA methylation via direct sequence-specific alterations in DNA-protein reactions; rather, methylation primarily affects chromatin structure [66-68].

TIMP-1 protein was not increased to the same extent as transcription following culture treatments. Discrepancies between TIMP-1 mRNA and protein have previously been reported [69]. and the amount of TIMP-1 translation is dependent upon the activation of a number of signalling pathways [70]. Furthermore, as TIMP-1 is secreted and has a short half-life, and as such the amount measured by western blotting in tissue explants only demonstrate the intracellular contribution of TIMP-1 production [71, 72].

The placenta itself is inherently variable, and significant intra-placental variation has been observed due to the vast range of cell types as well as normal variation in size, shape and weight [73]. There can also be considerable epigenetic variation within a placenta, so in addition to the effect of cell heterogeneity, there could also be random and localized effects of the uterine environment on the placental epigenome [73]. In light of this, every effort was taken to sample tissue widely across the placenta and fetal membranes.

\section{Conclusions}

Intrauterine infection is the leading identifiable cause of preterm birth, closely followed by PROM, and despite the implementation of antibiotic treatments to reduce perinatal morbidity and mortality, the incidence of preterm birth is in fact increasing [74, 75]. The use of inhibitors of metalloproteinases, in particular TIMP-1, provides an attractive option as a potential therapeutic agent. The marked increase of TIMP-1 that we have seen in gestational tissues in response to LPS in the context of altered chromatin structure by AZA therefore suggests that a pharmacological agent that modifies chromatin structure could be used as a therapeutic agent in women with intrauterine infection and who are at a greater risk of premature rupture of the fetal membranes.

\section{Competing interests \\ The authors declare that they have no competing interests.}

\section{Authors' contributions}

ZLV performed all the experiments, analysis and wrote the manuscript; MDM gave over all guidance and help with manuscript editing; APP conceived the study and assisted with data analysis and interpretation and manuscript preparation. All authors read and approved the final manuscript.

\section{Acknowledgments}

We thank staff and patients at Auckland City Hospital for donation and collection of tissue samples. We also thank Dr Devaki De Silva for technical input. This work was funded by Gravida: National Centre for Growth and Development, Friends of the Liggins Fund and the University of Auckland Faculty Research Development Fund.

\section{Author details}

${ }^{1}$ Liggins Institute, University of Auckland, Private Bag 92019, Auckland 1142, New Zealand. ${ }^{2}$ Gravida: National Centre for Growth and Development, Palmerston North, New Zealand. ${ }^{3}$ University of Queensland Centre for Clinical Research, Brisbane, Australia. ${ }^{4}$ The Heart Foundation, Auckland, New Zealand.

Received: 1 September 2015 Accepted: 9 December 2015

Published online: 21 December 2015

\section{References}

1. Romero R, Espinoza J, Kusanovic JP, Gotsch F, Hassan S, Erez O, et al. The preterm parturition syndrome. BJOG. 2006;113(Suppl 3):17-42.

2. Hilder L, Costeloe K, Thilaganathan B. Prolonged pregnancy: evaluating gestation-specific risks of fetal and infant mortality. Br J Obstet Gynaecol. 1998;105(2):169-73.

3. Weiss A, Goldman S, Shalev E. The matrix metalloproteinases (MMPS) in the decidua and fetal membranes. Front Biosci. 2007;12:649-59.

4. Athayde N, Romero R, Gomez R, Maymon E, Pacora P, Mazor M, et al. Matrix metalloproteinases-9 in preterm and term human parturition. J Matern Fetal Med. 1999;8(5):213-9.

5. Fortunato SJ, Menon R, Lombardi SJ. Collagenolytic enzymes (gelatinases) and their inhibitors in human amniochorionic membrane. Am J Obstet Gynecol. 1997;177(4):731-41.

6. Fortunato SJ, Menon R, Lombardi SJ. MMP/TIMP imbalance in amniotic fluid during PROM: an indirect support for endogenous pathway to membrane rupture. J Perinat Med. 1999;27(5):362-8.

7. Vadillo-Ortega F, Hernandez A, Gonzalez-Avila G, Bermejo L, Iwata K, Strauss 3rd JF. Increased matrix metalloproteinase activity and reduced tissue inhibitor of metalloproteinases-1 levels in amniotic fluids from pregnancies complicated by premature rupture of membranes. Am J Obstet Gynecol. 1996;174(4):1371-6.

8. Riley SC, Leask R, Denison FC, Wisely K, Calder AA, Howe DC. Secretion of tissue inhibitors of matrix metalloproteinases by human fetal membranes, decidua and placenta at parturition. J Endocrinol. 1999;162(3):351-9.

9. Romero R, Chaiworapongsa T, Espinoza J, Gomez R, Yoon BH, Edwin S, et al. Fetal plasma MMP-9 concentrations are elevated in preterm premature rupture of the membranes. Am J Obstet Gynecol. 2002;187(5):1125-30.

10. McLaren J, Taylor DJ, Bell SC. Increased concentration of pro-matrix metalloproteinase 9 in term fetal membranes overlying the cervix before labor: implications for membrane remodeling and rupture. Am J Obstet Gynecol. 2000;182(2):409-16. 
11. Xu P, Alfaidy N, Challis JR. Expression of matrix metalloproteinase (MMP)-2 and MMP-9 in human placenta and fetal membranes in relation to preterm and term labor. J Clin Endocrinol Metab. 2002;87(3):1353-61.

12. Vadillo-Ortega F, Gonzalez-Avila G, Furth EE, Lei H, Muschel RJ, StetlerStevenson WG, et al. 92-kd type IV collagenase (matrix metalloproteinase-9) activity in human amniochorion increases with labor. Am J Pathol. 1995;146(1):148-56.

13. Locksmith GJ, Clark P, Duff P, Saade GR, Schultz GS. Amniotic fluid concentrations of matrix metalloproteinase 9 and tissue inhibitor of metalloproteinase 1 during pregnancy and labor. Am J Obstet Gynecol. 2001;184(2):159-64.

14. Uchide K, Ueno H, Inoue M, Sakai A, Fujimoto N, Okada Y. Matrix metalloproteinase- 9 and tensile strength of fetal membranes in uncomplicated labor. Obstet Gynecol. 2000;95(6 Pt 1):851-5.

15. Athayde N, Edwin SS, Romero R, Gomez R, Maymon E, Pacora P, et al. A role for matrix metalloproteinase-9 in spontaneous rupture of the fetal membranes. Am J Obstet Gynecol. 1998;179(5):1248-53.

16. Fortunato SJ, Menon R, Lombardi SJ. Amniochorion gelatinase-gelatinase inhibitor imbalance in vitro: a possible infectious pathway to rupture. Obstet Gynecol. 2000;95(2):240-4.

17. Garcia-Lopez G, Vadillo-Ortega F, Merchant-Larios H, Maida-Claros R, Osorio $M$, Soriano-Becerril $D$, et al. Evidence of in vitro differential secretion of 72 and $92 \mathrm{kDa}$ type IV collagenases after selective exposure to lipopolysaccharide in human fetal membranes. Mol Hum Reprod. 2007; 13(6):409-18.

18. Maymon E, Romero R, Pacora P, Gervasi MT, Gomez R, Edwin SS, et al. Evidence of in vivo differential bioavailability of the active forms of matrix metalloproteinases 9 and 2 in parturition, spontaneous rupture of membranes, and intra-amniotic infection. Am J Obstet Gynecol. 2000;183(4):887-94.

19. Zaga-Clavellina V, Garcia-Lopez G, Flores-Pliego A, Merchant-Larios H, VadilloOrtega F. In vitro secretion and activity profiles of matrix metalloproteinases, MMP-9 and MMP-2, in human term extra-placental membranes after exposure to Escherichia coli. Reprod Biol Endocrinol. 2011;9:13.

20. Parry S, Strauss 3rd JF. Premature rupture of the fetal membranes. N Engl J Med. 1998;338(10):663-70.

21. Asrat T. Intra-amniotic infection in patients with preterm prelabor rupture of membranes. Pathophysiology, detection, and management. Clin Perinatol. 2001;28(4):735-51.

22. Romero R, Espinoza J, Goncalves LF, Kusanovic JP, Friel LA, Nien JK. Inflammation in preterm and term labour and delivery. Semin Fetal Neonatal Med. 2006;11(5):317-26.

23. Romero R, Roslansky P, Oyarzun E, Wan M, Emamian M, Novitsky TJ, et al. Labor and infection. II. Bacterial endotoxin in amniotic fluid and its relationship to the onset of preterm labor. Am J Obstet Gynecol. 1988;158(5):1044-9.

24. Gomez R, Romero R, Edwin SS, David C. Pathogenesis of preterm labor and preterm premature rupture of membranes associated with intraamniotic infection. Infect Dis Clin North Am. 1997;11(1):135-76.

25. Jones PA. Functions of DNA methylation: islands, start sites, gene bodies and beyond. Nat Rev Genet. 2012;13(7):484-92.

26. Bird AP. CpG-rich islands and the function of DNA methylation. Nature. 1986:321(6067):209-13.

27. Siegfried Z, Eden S, Mendelsohn M, Feng X, Tsuberi BZ, Cedar H. DNA methylation represses transcription in vivo. Nat Genet. 1999:22(2):203-6.

28. Santos F, Hendrich B, Reik W, Dean W. Dynamic reprogramming of DNA methylation in the early mouse embryo. Dev Biol. 2002;241(1):172-82.

29. Cotton AM, Avila L, Penaherrera MS, Affleck JG, Robinson WP, Brown CJ. Inactive $X$ chromosome-specific reduction in placental DNA methylation. Hum Mol Genet. 2009;18(19):3544-52.

30. Rahnama F, Shafiei F, Gluckman PD, Mitchell MD, Lobie PE. Epigenetic regulation of human trophoblastic cell migration and invasion. Endocrinology. 2006;147(11):5275-83.

31. Chavan-Gautam P, Sundrani D, Pisal H, Nimbargi V, Mehendale S, Joshi S Gestation-dependent changes in human placental global DNA methylation levels. Mol Reprod Dev. 2011;78(3):150.

32. Novakovic B, Yuen RK, Gordon L, Penaherrera MS, Sharkey A, Moffett A, et al. Evidence for widespread changes in promoter methylation profile in human placenta in response to increasing gestational age and environmental/stochastic factors. BMC Genomics. 2011:12:529.

33. Sitras V, Fenton C, Paulssen R, Vartun A, Acharya G. Differences in gene expression between first and third trimester human placenta: a microarray study. PLoS One. 2012;7(3):e33294.
34. Lee KJ, Shim SH, Kang KM, Kang JH, Park DY, Kim SH, et al. Global gene expression changes induced in the human placenta during labor. Placenta. 2010;31(8):698-704.

35. Sitras V, Paulssen RH, Gronaas H, Vartun A, Acharya G. Gene expression profile in labouring and non-labouring human placenta near term. Mol Hum Reprod. 2008;14(1):61-5.

36. Chelbi ST, Mondon F, Jammes H, Buffat C, Mignot TM, Tost J, et al. Expressional and epigenetic alterations of placental serine protease inhibitors: SERPINA3 is a potential marker of preeclampsia. Hypertension. 2007;49(1):76-83.

37. Wang Z, Lu S, Liu C, Zhao B, Pei K, Tian L, et al. Expressional and epigenetic alterations of placental matrix metalloproteinase 9 in preeclampsia. Gynecol Endocrinol. 2009;26(2):96-102.

38. Yuen RK, Penaherrera MS, von Dadelszen P, McFadden DE, Robinson WP. DNA methylation profiling of human placentas reveals promoter hypomethylation of multiple genes in early-onset preeclampsia. Eur J Hum Genet. 2010;18(9):1006-12

39. Yuan BZ, Jefferson AM, Popescu NC, Reynolds SH. Aberrant gene expression in human non small cell lung carcinoma cells exposed to demethylating agent 5-aza-2'-deoxycytidine. Neoplasia. 2004;6(4):412-9.

40. Missiaglia E, Donadelli M, Palmieri M, Crnogorac-Jurcevic T, Scarpa A, Lemoine NR. Growth delay of human pancreatic cancer cells by methylase inhibitor 5-aza-2'-deoxycytidine treatment is associated with activation of the interferon signalling pathway. Oncogene. 2005;24(1):199-211.

41. Ricca TI, Liang G, Suenaga AP, Han SW, Jones PA, Jasiulionis MG. Tissue inhibitor of metalloproteinase 1 expression associated with gene demethylation confers anoikis resistance in early phases of melanocyte malignant transformation. Transl Oncol. 2009;2(4):329-40.

42. MacDougall JR, Bani MR, Lin Y, Muschel RJ, Kerbel RS. 'Proteolytic switching': opposite patterns of regulation of gelatinase $B$ and its inhibitor TIMP-1 during human melanoma progression and consequences of gelatinase $B$ overexpression. Br J Cancer. 1999:80(3-4):504-12

43. Veerla S, Panagopoulos I, Jin Y, Lindgren D, Hoglund M. Promoter analysis of epigenetically controlled genes in bladder cancer. Genes Chromosomes Cancer. 2008;47(5):368-78.

44. Logan PC, Ponnampalam AP, Rahnama F, Lobie PE, Mitchell MD. The effect of DNA methylation inhibitor 5-Aza-2'-deoxycytidine on human endometrial stromal cells. Hum Reprod. 2010;25(11):2859-69.

45. Mitchell MD. Unique suppression of prostaglandin $\mathrm{H}$ synthase-2 expression by inhibition of histone deacetylation, specifically in human amnion but not adjacent choriodecidua. Mol Biol Cell. 2006;17(1):549-53.

46. Sato TA, Mitchell MD. Molecular inhibition of histone deacetylation results in major enhancement of the production of IL-1beta in response to LPS. Am J Physiol Endocrinol Metab. 2006;290(3):E490-3.

47. Simpson KL, Keelan JA, Mitchell MD. Labor-associated changes in interleukin-10 production and its regulation by immunomodulators in human choriodecidua. J Clin Endocrinol Metab. 1998:83(12):4332-7.

48. Yuen RK, Avila L, Penaherrera MS, von Dadelszen P, Lefebvre L, Kobor MS, et al. Human placental-specific epipolymorphism and its association with adverse pregnancy outcomes. PLoS One. 2009;4(10):e7389.

49. Cotton AM, Lam L, Affleck JG, Wilson IM, Penaherrera MS, McFadden DE, et al. Chromosome-wide DNA methylation analysis predicts human tissuespecific X inactivation. Hum Genet. 2011;130(2):187-201.

50. Anderson CL, Brown CJ. Epigenetic predisposition to expression of TIMP1 from the human inactive X chromosome. BMC Genet. 2005:6:48.

51. Anderson CL, Brown CJ. Variability of $X$ chromosome inactivation: effect on levels of TIMP1 RNA and role of DNA methylation. Hum Genet. 2002:110(3):271-8.

52. Kim-Fine S, Regnault TR, Lee JS, Gimbel SA, Greenspoon JA, Fairbairn J, et al. Male gender promotes an increased inflammatory response to lipopolysaccharide in umbilical vein blood. J Matern Fetal Neonatal Med. 2012;25(11):2470-4.

53. De Larco JE, Wuertz BR, Yee D, Rickert BL, Furcht LT. Atypical methylation of the interleukin-8 gene correlates strongly with the metastatic potential of breast carcinoma cells. Proc Natl Acad Sci U S A. 2003;100(24):13988-93.

54. Unoki M, Nakamura Y. Methylation at CpG islands in intron 1 of EGR2 confers enhancer-like activity. FEBS Lett. 2003;554(1-2):67-72.

55. Niesen MI, Osborne AR, Yang H, Rastogi S, Chellappan S, Cheng JQ, et al. Activation of a methylated promoter mediated by a sequence-specific DNA-binding protein. RFX J Biol Chem. 2005;280(47):38914-22.

56. Xiong W, Tapprich WE, Cox GS. Mechanism of gonadotropin gene expression. Identification of a novel negative regulatory element at the transcription start site of the glycoprotein hormone alpha-subunit gene. J Biol Chem. 2002;277(43):40235-46. 
57. Cox GS, Gutkin DW, Haas MJ, Cosgrove DE. Isolation of an Alu repetitive DNA binding protein and effect of CpG methylation on binding to its recognition sequence. Biochim Biophys Acta. 1998;1396(1):67-87.

58. Li W, Unlugedik E, Bocking AD, Challis JR. The role of prostaglandins in the mechanism of lipopolysaccharide-induced proMMP9 secretion from human placenta and fetal membrane cells. Biol Reprod. 2007;76(4):654-9.

59. Arechavaleta-Velasco F, Koi H, Strauss 3rd JF, Parry S. Viral infection of the trophoblast: time to take a serious look at its role in abnormal implantation and placentation? J Reprod Immunol. 2002;55(1-2):113-21.

60. Fortunato SJ, Menon R, Lombardi SJ. Support for an infection-induced apoptotic pathway in human fetal membranes. Am J Obstet Gynecol. 2001; 184(7):1392-7. discussion 7-8

61. Buhimschi IA, Kramer WB, Buhimschi CS, Thompson LP, Weiner CP. Reduction-oxidation (redox) state regulation of matrix metalloproteinase activity in human fetal membranes. Am J Obstet Gynecol. 2000;182(2):458-64.

62. Lim R, Barker G, Wall CA, Lappas M. Dietary phytophenols curcumin, naringenin and apigenin reduce infection-induced inflammatory and contractile pathways in human placenta, foetal membranes and myometrium. Mol Hum Reprod. 2013;19(7):451-62.

63. Egger G, Liang G, Aparicio A, Jones PA. Epigenetics in human disease and prospects for epigenetic therapy. Nature. 2004;429(6990):457-63.

64. Qin T, Jelinek J, Si J, Shu J, Issa JP. Mechanisms of resistance to 5-aza-2'deoxycytidine in human cancer cell lines. Blood. 2009;113(3):659-67.

65. Couillard J, Esteve PO, Pradhan S, St-Pierre Y. 5-Aza-2'-deoxycytidine and interleukin-1 cooperate to regulate matrix metalloproteinase-3 gene expression. Int J Cancer. 2011;129(9):2083-92.

66. Litt MD, Hansen RS, Hornstra IK, Gartler SM, Yang TP. 5-Azadeoxycytidineinduced chromatin remodeling of the inactive X-linked HPRT gene promoter occurs prior to transcription factor binding and gene reactivation. J Biol Chem. 1997;272(23):14921-6.

67. Pfeifer GP, Steigerwald SD, Hansen RS, Gartler SM, Riggs AD. Polymerase chain reaction-aided genomic sequencing of an $X$ chromosome-linked CpG island: methylation patterns suggest clonal inheritance, CpG site autonomy, and an explanation of activity state stability. Proc Natl Acad Sci U S A. 1990; 87(21):8252-6.

68. Pfeifer GP, Tanguay RL, Steigerwald SD, Riggs AD. In vivo footprint and methylation analysis by PCR-aided genomic sequencing: comparison of active and inactive $X$ chromosomal DNA at the CpG island and promoter of human PGK-1. Genes Dev. 1990;4(8):1277-87.

69. Lichtinghagen R, Musholt PB, Lein M, Romer A, Rudolph B, Kristiansen G, et al. Different mRNA and protein expression of matrix metalloproteinases 2 and 9 and tissue inhibitor of metalloproteinases 1 in benign and malignant prostate tissue. Eur Urol. 2002;42(4):398-406.

70. Wilczynska KM, Gopalan SM, Bugno M, Kasza A, Konik BS, Bryan L, et al. A novel mechanism of tissue inhibitor of metalloproteinases-1 activation by interleukin-1 in primary human astrocytes. J Biol Chem. 2006:281(46):34955-64.

71. Lambert E, Dasse E, Haye B, Petitfrere E. TIMPs as multifacial proteins. Crit Rev Oncol Hematol. 2004:49(3):187-98.

72. Brew K, Nagase $H$. The tissue inhibitors of metalloproteinases (TIMPS): an ancient family with structural and functional diversity. Biochim Biophys Acta. 2010;1803(1):55-71.

73. Avila L, Yuen RK, Diego-Alvarez D, Penaherrera MS, Jiang R, Robinson WP. Evaluating DNA methylation and gene expression variability in the human term placenta. Placenta. 2010;31(12):1070-7.

74. lams JD, Romero R, Culhane JF, Goldenberg RL. Primary, secondary, and tertiary interventions to reduce the morbidity and mortality of preterm birth. Lancet. 2008:371(9607):164-75.

75. Goldenberg RL, Culhane JF, lams JD, Romero R. Epidemiology and causes of preterm birth. Lancet. 2008;371(9606):75-84

\section{Submit your next manuscript to BioMed Central and we will help you at every step:}

- We accept pre-submission inquiries

- Our selector tool helps you to find the most relevant journal

- We provide round the clock customer support

- Convenient online submission

- Thorough peer review

- Inclusion in PubMed and all major indexing services

- Maximum visibility for your research

Submit your manuscript at www.biomedcentral.com/submit
Biomed Central 